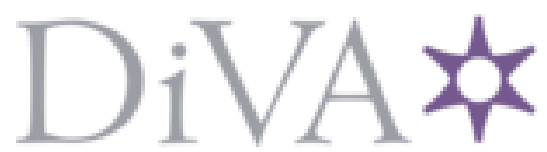

http://www.diva-portal.org

\title{
Postprint
}

This is the accepted version of a paper published in Digital Journalism. This paper has been peer-reviewed but does not include the final publisher proof-corrections or journal pagination.

Citation for the original published paper (version of record):

Holt, K., Ustad Figenschou, T., Frischlich, L. (2019)

Key Dimensions of Alternative News Media

Digital Journalism, 7(7): 860-869

https://doi.org/10.1080/21670811.2019.1625715

Access to the published version may require subscription.

N.B. When citing this work, cite the original published paper.

Permanent link to this version:

http://urn.kb.se/resolve?urn=urn:nbn:se:lnu:diva-85697 
See discussions, stats, and author profiles for this publication at: https://www.researchgate.net/publication/333603941

\section{Key Dimensions of Alternative News Media}

Preprint · June 2019

DOI: $10.1080 / 21670811.2019 .1625715$

CITATIONS

0

3 authors, including:

Holt Kristoffer

Gulf University for Science and Technology (Kuwait)

21 PUBLICATIONS 247 CITATIONS

SEE PROFILE

Some of the authors of this publication are also working on these related projects:

Project $\quad$ Join me in death: Managing mortality salience via mediated social encounters View project

PropStop: Identification, detection, and combating of hidden propaganda attacks via online media View project
READS

68

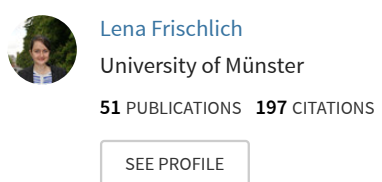




\section{Key Dimensions of Alternative News Media}

Kristoffer Holt, Dept. of Mass Communication and Media (MCM)

Gulf University for Science and Technology, Kuwait. Holt.A@gust.edu.kw

Tine Ustad Figenschou, Dept. of Journalism and Media Studies

Oslo Metropolitan University, Norway. tineuf@oslomet.no

Lena Frischlich, Dept. of Communication

University of Münster, Germany. lena.frischlich@uni-muenster.de

Preprint: Holt, Figenschou \& Frischlich (2019), Key Dimensions of Alternative News Media, Digital Journalism, forthcoming.
Abstract (200 words)

This article proposes a definition of alternative news media and suggests routes for further research. It complements and extends previous conceptualizations in research on alternative media and outlines an umbrella definition of this phenomenon aimed to inspire contemporary research and scholarly debate. Previous research has been guided by a 'progressive' perspective as a form of resistance against 'bourgeois' hegemonic discourse. Such normative evaluations have in turn limited how the phenomenon has been studied empirically, by limiting the scope of research so that important contemporary phenomena fall outside the theoretical map. Conceptualizing alternative news media in the present hybrid and polarized media environment, we first propose a non-normative, multilevel relational definition: Alternative news media position themselves as correctives of the mainstream news media, as expressed in editorial agendas or statements and/or are perceived as such by their audiences or third-parties. This counter-hegemonic alternativeness can emerge on the macro level of societal function, the meso-level of organizations and/or the micro level of news content and producers. Second, demonstrating why this umbrella definition is fruitful in the changing media environment characterized by boundary struggles, crisis in legacy news media and mushrooming of alternative news outlets, we highlight research gaps and propose future research.

Keywords: Alternative media, mainstream media, definition, counter-publics, digital journalism, news media 


\section{Alternative media in previous research: Merits and}

\section{problems}

Since the turn of the millennium, scholarly attention to alternative forms of (news) media has increased (see Rauch (2007) and Atton (2015) for informative overviews) and has illuminated the phenomenon from different angles: Proposing a broader theoretical and methodological research framework, Atton (2002a) distinguishes between alternative (news) media as a product (highlighting radical, counter-hegemonic content and news values, alternative aesthetics and forms and non-advertising) and as a process (anti-copyright culture, de-professionalization, native reporting, collective organization and alternative distribution). Often, the active positioning vis-àvis, the challenge to and critique of legacy media and professional journalists have been a defining characteristic of various alternative media. Not surprising, alternative media have been practiced and understood primarily as alternative or even opposition to the legacy or mainstream media (Harcup, 2005). This position of alternative news media-in opposition to the so-called mainstream - represent the first key dimension in our definition, as digital affordances make the public arena more accessible for an increasing number of actors.

The term 'mainstream news media' is frequently used in the literature and plays a crucial role in alternative news media's self-perception. For instance, the Russian-tied network RT.com, a controversial yet prominent medium globally, claims to cover "stories overlooked by the mainstream media" (25.02.2019). We understand mainstream news media as a societal system that is formed by specific legacy news media organizations which themselves are characterized by certain, often hierarchical, organizational structures and traditional publishing routines. They fulfil a societal function by enabling public discourse through the provision of topics of general interest, that are oriented on facts, selected by professional actors, and published following professional rules (Steindl, Laurer \& Hanitzsch, 2017). Although in hybrid media systems (Chadwick, 2013) the borders of what constitutes journalism are increasingly blurred (Steindl et al, 2017) and the dominance of these mainstream media might be fading, they still reach the largest share of audiences (Newman et al, 2018).

In alternative news media, the mainstream media have largely been understood in monolithic, simplistic perceptions as one dominant bloc-corrupted by, dependent on and uncritical of the establishment. In influential early scholarly perceptions, such binary oppositions were often 
reproduced and strengthened. In much early literature alternative media were characterized as democratic, open and non-hierarchical campaigners for social justice-using collective modes of organization with a radical, leftist political agenda and close ties to social movements (see Negt \& Kluge, 1972; Fuchs, 2010, and Hájek \& Carpentier, 2015). Mainstream media, on the other hand, were characterized as a uniform, profit-seeking and hierarchically organized bloc, with a routinized and professionalized journalism that was implicitly understood as being elitist and exclusive. Noteworthy, this dichotomization has been criticized for presenting alternative media as an ideal type of 'purer' media, contrasted with the 'elitism' and 'corruption' of professional media (Atton, 2002b, Bailey, Cammaerts \& Carpentier, 2008, or Downing, 2001, himself ân early proponent of the dichotomous approach).

The academic idealizations of alternative media have recently been nuanced in two important ways: First, alternative and mainstream news media have been analysed as a continuum rather than as absolutely opposed categories (Atton 2002a/b, 2015; Hackett \& Gurleyen, 2015; Kenix, 2011; Rauch, 2007)-a notion that is even more important in the contemporary hybrid media system. Second, scholars have emphasized the pitfalls of an absence of professionalism in alternative media, stressing financial and organizational instability, low technological resources, know-how and fragmented audiences (Atton, 2002a; Downey \& Fenton, 2003), resulting in internal struggles or a lack of political influence. Other studies have raised the question about how far alternative media live up to their own ideals instead of being platforms where elite activists dominate. Despite these important problematizations, we argue that the concept of 'alternative media' remain largely reserved for alternative media initiatives positioned on the ideological and political 'Left'. Hence, multiple recent media phenomena which challenge mainstream media from ideological positions on the far-right or from positions of religious conservatism, largely falls outside this literature.

In recent years, a growing number of online news sites, blogs and forums positioned right of the conservative-centre label themselves 'alternative right' media or simply 'alternative media' (Holt, 2018). Such use of the term 'alternative' has been criticized as a neologism to re-brand ideologies and political ideas long seen as 'unacceptable' for the mainstream discourse (such as white nationalism), and as an exploitation of the mainstream news media's fascination with novelty, but nevertheless remain a meaningful construal of terms for many (Holt, 2018; Marwick \& Lewis, 2017, 11). 
How should we as scholars understand such new media? First, we argue that the academic and popular debate regarding whether such right-wing media (from radical right to extreme right) can be conceptualized as alternative, and the flourishing of related terms such as hyper-partisan media, makes the implicit normative perception of 'alternative media' visible. Second, studies have shown that far-right online media (and other new media initiatives) often employ similar discursive strategies on power, hegemony and resistance as other alternative media, positioning themselves as 'outsiders' and 'critics', marginalized by and in opposition to 'the mainstream media hegemony' (Haller \& Holt, 2018; Figenschou \& Ihlebæk, 2018). Because contemporary rightwing alternative media both rely on and strategically use the same counter-hegemonic discourses as other alternative news media, we argue that it is fruitful to study and theorize these new phenomena in relation to the extant body of literature. Third, this does not mean that these counterhegemonic power discourses are not employed strategically, but rather than debating whether right-wing alternative media can live up to the previous, largely normative interpretations of alternative media, we propose a non-ideological umbrella definition, accounting for different levels or key dimensions on which news media can differ along the mainstream - alternative continuum. Against this background, we offer a definition that allows for research independently of a media initiative's ideological position, while still building on prior valuable contributions that have laid ground for theorizing these phenomena.

\section{Proposed definition - a relational, multilevel approach}

In our opinion, alternative news media should be considered first and foremost in the light of a position as a self-perceived corrective of 'traditional', 'legacy' or 'mainstream' news media in a given socio-cultural and historical context:

Alternative news media represent a proclaimed and/or (self-) perceived corrective, opposing the overall tendency of public discourse emanating from what is perceived as the dominant mainstream media in a given system. This stated "alternativeness" can emerge on and should be studied on multiple different levels: Alternative news media can publish different voices (alternative content creators) trying to influence public opinion according to an agenda that is perceived by their promoters and/or audiences as underrepresented, ostracized or otherwise marginalized in mainstream news media, alternative accounts and 
interpretations of political and social events (alternative news content), rely on alternative publishing routines via alternative media organizations and/or through channels outside and unsupported by the major networks and newspapers in an alternative media system.

Such an umbrella definition takes a relational approach as a point of departure. In other words; the alternative quality of any news medium is derived from claims to its counter-or complementary position to a certain hegemony, since this must be construed as the organizing principle behind alternative media enterprises. The corrective, counter-hegemonic aspiration can be addressed from up to three perspectives: the self-perception of the media owners or content producers (e.g. reported in interviews, proclaimed in editorial agendas or mission statements). The audience perception (e.g. stated in surveys or interviews), or the perception as of a third party, for instance competitors or political authorities. Evaluations of alternativeness can differ depending on the perspective: A news medium can proclaim its alternativeness without being perceived as such by others and vice versa. Explicitly reporting the perspective taken in a given study is thus a crucial step towards systematizing the research field.

By our definition we aim to define and study a phenomenon that is increasingly widespread and relevant to public discourse in our age. Media of different positions that promise to oppose what they see as dominant and elitist agenda-setting mainstream news media shaping the worldviews of citizens in a way they oppose.

Beyond clarifying the perspective examined, it is crucial for researchers aiming to analyse such counter-hegemonic aims to identify and study dimensions of alternative media on one or multiple levels - the producer, content, organizational and system level. Our definition is therefore an umbrella term using a multi-level approach describing key dimensions of alternativeness: Drawing from prior research (e.g., Frischlich, Boberg, \& Quandt, 2019, Shoemaker \& Reese, 2014, Hanitzsch et al, 2019), we suggest that defining and studying alternative media benefits from specifying the level(s) on which a given case (self-)positions as alternative:

The individual micro-level of content producers - whether the proprietary content is mostly produced by journalists or alternative producers such as citizen journalists or activistsrepresent one key dimension of alternative news media. Although many writers and editors in alternative media also have professional backgrounds from the mainstream media (see Harcup, 
2005, Figenschou \& Ihlebæk, 2018), alternative media have traditionally been associated with a democratic-bottom up inclusion of non-professionals such as fans, native journalists, marginalized groups or citizens (see Atton, 2015). The far-right-wing blog PI-news in Germany, for example, offers its readers the easy option to become a 'reporter' by anonymously publishing own content or 'interesting' content published elsewhere (25.02.2019).

A second dimension on the micro-level address differences regarding the publishing of alternative news content, content that provides "alternative accounts and interpretations of political and social events" or uses different formats (although not necessarily different channels: different news media can fill the same Facebook feed or show up on the same google request). In alternative news articles, the self-perceived corrective function-is particularly visible. Alternative media often publish content that is politically and/or socially/culturally radical, counterhegemonic, or alternative in its epistemological foundations. To do so, alternative news often emphasize special interest which can differ from traditional news regarding its core information, meta information, or the context in which it is embedded. The counter-hegemonic aim comprise new news genre(s) challenging established news formats (i.e. distinguishing between facts and opinion). Scandinavian immigration critical alternative media, for example, largely share the same ideological position, but employ different journalistic styles and functions (Nygaard, 2019).

Differences on the meso-level of alternative media organizations and their production and distribution processes (e.g. ultra-right-wing outlets in comparison to legacy national newspapers) represent another dimension: For instance, political blogs, compared to traditional printed newspapers are often produced at low costs, and radical progressive alternative media are often collectively non-hierarchically organized. Alternative news production can also advocate specific normative ideals (e.g. ideals of objectivity vs. ideological truth) and/or prioritize different news values (e.g., anti-capitalism, anti-immigration, anti-Western), use different sourcing practices (establishment elites vs. voiceless grass-root sources or critics), or establish different audience relations, for instance passive vs. participatory (Harcup, 2005). The network of the selfdeclared 'Islamic State' ('IS' or 'daesh'), for example, relied primarily on its own news agencies (Amaq), published own magazines (e.g. Dabiq), selecting 'news' based on ideological values. Other alternative news media and movements, such as for example Pegida, largely rely on and reframe mainstream news media and news agency content (Haller \& Holt, 2018). Today, alternative news is primarily distributed in social, networked media, where opinionated, emotional 
and visually striking content, is widely shared (i.e. Marwick \& Lewis, 2017). Partially, large scale platforms such as Facebook or Twitter are thereby considered themselves as part of the "mainstream" and supplemented by self-declared alternative services such as gab.ai, the selfdeclared "social network that champions free speech, individual liberty and the free flow of information online" (self-description, 2019/03/26).

On the macro-level alternativeness can be located on the level of entire media systems such as the ecosystem of the alt-right alternative media versus the national legacy news system (e.g., Marwick \& Lewis, 2017). Although the two systems can be mutually interwoyen, there are systempreserving tendencies on both poles. The New Yorker's attempt to invite Steve Bannon (previously a front figure for alternative Breitbart News) to its 2018 festival raised enormous outrage among other legacy news media culminating in a retraction of the invitation (see Pengelly, 2018/09/04 in the Guardian). At the same time, right-wing alternative medias" outrage about the "system media" or the "liar press" explicitly positions themselves in an opposition the mainstream (see Lane, 2015/03/16 in Breitbart.com). In addition, how/alternative media relate to the established professional institutions (i.e. journalist or editor associations), regulatory systems (i.e. selfregulatory boards) and national media policy (i.e. press subsidies and regulation) - illuminate contemporary alternative media phenomenon. In Norway for example, the editor of the immigration critical alternative news site (Document.no) was granted membership in the Association of Norwegian Editors (in August 2018)- a decision which caused major debate about who are legitimate journalistic actors.

These key dimensions are not proposed as a 'diagnostic tool', to verify whether a news media is objectively 'alternative' or not. The various dimensions of our umbrella definition are not mutually constitutive, but rather serve as positions of alternativeness on a continuum. Beyond the perceived counter-hegemonic aim, which in our relational definition is the defining aspect, multiple combinations of alternativeness are possible, and often probable, although not necessary. How and on what level the counter-hegemonic agenda is played out, is a question for empirical, contextualized research. In essence, the more a given medium differs from the mainstream, the more likely it is that it is perceived as an alternative serving the function of remedying some ill or compensating for deficits associated with the mainstream. Overall, the relationship between alternative and mainstream remains complex and hybrid (Harcup, 2005). Particularly the increased relevance of aggregator platforms such as Google or Facebook and the submission to the digital 
societies 24/7 availability fosters the dissolution of boundaries between mainstream and alternative news media, calling for more empirically-grounded analysis of the boundaries and boundary struggles between the two poles. Figure 1 summarizes the different characteristics at the two poles.

\section{Figure 1. Alternative news media in relation to mainstream media (MSM).}

(Figure 1. About here)

These levels - embedded in a certain socio-cultural context and subject to historical and political conditions - underscore how this relational approach is dynamic: Positions can rapidly change in public discourse and the boundaries between what is considered as legitimate/mainstream discourse and who is considered deviant and outside the sphere of legitimate controversy (Hallin, 1989) is dynamic, contextual and subject to change. The alternative can become the mainstream and vice versa. For instance, the former online news blog Huffington Post has recently ended its unpaid blogger program and focusses increasingly on professional news publishing. As such, it would be considered more mainstream now compared to the Huffington Post of 2005 following our definition. At the same time, former mainstream media can be declared as alternative, subversive or transgressive after regime changes such as observed recently in Turkey or Hungary. Such changes of alternativeness might be fuelled by the overall hybridization of media systems, blurring the lines between different media systems. Nevertheless, the proposed definition can serve as justification of why a concrete case is deemed as being alternative by identifying the perspective taken and the level(s) of analysis (article, producer, organization, or system).

\section{Future research}

The umbrella definition proposed here aims to serve as a starting point for scholarly pursuit of pressing issues in today's hybrid media landscape, marked by polarization, culture wars and algorithmic warfare in the digital realm. By considering alternative news media as an 'alternative' and 'in regards' to - allows to put them into context. It accommodates alternative news media inspired by diverse political (left- as well as right-wing), religious (e.g. fundamentalist or extreme liberal), or philosophical (e.g. animal rights) ideologies that outspokenly describe themselves as counter-hegemonic correctives to mainstream news media or are described as such by their 
audience or third-parties. As such, our definition encourages further scrutiny of similarities and differences between them while at the same time pointing out specific areas where more research is needed. In the following we will emphasize some of these:

Firstly, adopting the relational multi-level definition puts focus on the need to distinguish between alternative news media in different media systems. For example, there is a huge difference between alternative media in totalitarian or authoritarian states compared to alternative media in democratic liberal states. There is a need to acknowledge alternative news medija from different macro-level perspectives (ideological, cultural, religious, geopolitical), but also the organizational and individual levels need to be studied through different contextual lenses. International comparative studies of alternative news media in different media systems would help refining our knowledge about the general characteristics of alternative news media across contexts.

Secondly, as debates about how to understand the mushrooming of alternative media and their relation to the rise of populism are raging, there is a need for further analysis of the impact of alternative news media. Today, there is little information on the reach of right-wing alternative media. There have been attempts at measuring this, but overall, the research gap is large, which leaves the field open for speculations (over-or under estimating importance as driver of public opinion). Further, research trying to find trustworthy and solid ways to measure the impact of these media and compare it to other media would be much needed.

Thirdly, our knowledge about audiences of alternative media and especially their motivations and gratifications is still scarce. Particularly when alternative media are concerned (i.e. Islamic extremist publications), more research is needed that examines assumptions of 'echochambers and fears of online 'radicalization', especially considering other dictums that point to a hybrid media climate, where audience members combine their diet from a variety of sources. Furthermore, there is little known about how the algorithms and various attempts to filter disinformation and hate speech work in relation to steering audiences to or away from different news media sources.

As a fourth suggestion, our definition also highlights an aspect that has been given little attention in previous research: The business-models of alternative news media. Some alternative news media have managed to attract paying audiences or other sources of income, such as advertising revenue through YouTube. Others are backed by organizations (or states) with an interest in intervening in public discourse (for political, cultural, religious or financial reasons). 
The financial aspects are crucial for the existence of both mainstream and alternative news media and this opens up for a field of unexplored terrain. It also underlines the role of tech giants who can demonetize alternative news media not considered in compliance with their values.

Lastly, ongoing changes in the mainstream/alternative continuum deserves more scholarly attention: As some alternative news media become more influential, with wider distribution, larger audiences and more engaged producers, it is vital to study to how such professionalization processes impact on the counter-hegemonic positions. If alternative news media start to recruit professional journalists, seek membership in established press organizations, and aim to position themselves more clearly within the professional journalistic field-is that a 'mainstreaming' of the alternative or a polarization/politicization of the mainstream? What changes does such professionalization entail within alternative media and how is it met by professional media organizations and the broader media institutions?

\section{Concluding remarks}

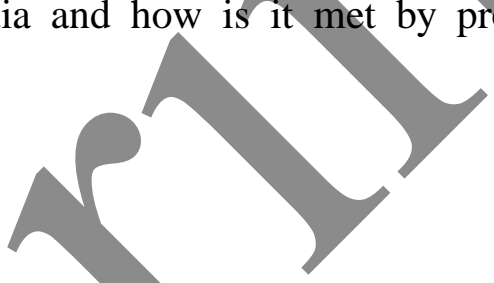

We argue that it is necessary to critically evaluate and move forward from the way alternative news media have previously been normatively evaluated and studied empirically. Our proposed umbrella definition of alternative news media and our framework for future research provides one starting point. The advantage of our relational approach to alternative media is that much of the insights and benefits of previous research can be applied, but to a wider range of cases than before, while at the same time such developments opens up for new questions to be asked - on the societal, organizational as well as on the individual and content level, examining the perspective of content producers, audiences, and competitors. This is the direction we suggest, hoping that future research will elaborate on the key dimensions of alternative media presented here. The suggested areas for future research are also, for reasons of limited space, overly compact and more areas in need of future research are quite evident: the epistemological dimension in relation to current debates over 'fake news' and 'alternative facts'; the individuals who are active in alternative media; the surrounding media landscape and its handling of the emergence of alternative media, especially online; the nature of the published content, to name a few.

Lastly, we view this article as an addendum to the large body of valuable prior work on alternative (news) media. However, we have found ourselves limited in our own research when trying to operationalize the framework of the pre-existing theory, which mainly is to be found 
within the critical school. We hope that our approach encourages research beyond ideological preference while simultaneously allowing for the inclusion of prior work in this area.

\section{Literature}

Atton, C. (2002a). Alternative media London: Sage.

Atton, C. (2002b). News cultures and new social movements: radical journalism and the mainstream media. Journalism Studies 3(4), 491-505.

Atton, C. (Ed.) (2015). The Routledge companion to alternative and community media. London: Routledge.

Bailey, O. G., B. Cammaerts \& N. Carpentier (2008). Understanding Alternativé Media. Maidenhead: Open University Press.

Chadwick, A. (2013). The hybrid media system: Politics and power. Oxford: Oxford University Press.

Downey, J., \& Fenton, N. (2003). New Media, Counter Publicity and the Public Sphere. New Media \& Society, 5(2), 185-202.

Downing, J. D. H. (2001). Radicat media: Rebellious communication and social movements. Thousand Oaks: Sage Publications.

Figenschou, T. U., \& Ihlebæk, K. A. (2018). Challenging Journalistic Authority: Media criticism in far-right alternative media. Journalism Studies, DOI: 10.1080/1461670X.2018.1500868.

Frischlich, L., Boberg, S. \& Quandt, T. (2019) Comment Sections as Targets of Dark Participation? Journalists' Evaluation and Moderation of Deviant User Comments, Journalism Studies, DOI: 10.1080/1461670X.2018.1556320.

Fuchs, C. (2010). Alternative media as critical media. European Journal of Social Theory, 13(2), 173-192. https://doi.org/10.1177/1368431010362294

Hackett, R. A., \& Gurleyen, P. (2015). Beyond the binaries? Alternative media and objective journalism. In C. Atton (Ed.) The Routledge Companion to Alternative and Community Media, London: Routledge, 54-65.

Haller, A., \& Holt, K. (2018). Paradoxical populism: how PEGIDA relates to 
mainstream and alternative media. Information, Communication \& Society, DOI:10.1080/1369118X.2018.1449882.

Hallin, D. C. (1989). The uncensored war: The media and Vietnam. University of California Press.

Hanitzsch, T., Hanusch, F., Ramaprasad, J., \& de Beer, A. S. (2019, in press). Worlds of journalism - Journalistic culture around the globe. New York: Columbia University Press.

Harcup, T. (2005). "I'm Doing this to Change the World": journalism in alternative and mainstream media. Journalism Studies, 6(3), 361-374.

Hájek, R. \& Carpentier, N. (2015). Alternative mainstream media in the Czech Republic: beyond the dichotomy of alternative and mainstream media, Continuum, 29(3), 365-382, DOI: 10.1080/10304312.2014.986061.

Holt, K. (2018). Alternative Media and the Notion of Anti-Systemness: Towards an Analytical Framework. Media and Communication, 6(4), 49-57.

Kenix, L. J. (2011). Alternative and mainstream media: The converging spectrum. London \& New York: Bloomsbury Academic.

Negt, O. \& Kluge, A. (1972). Public Sphere and Experience: Towards an Analysis of the Bourgeois and Proletarian Public Sphere. Minneapolis: University of Minnesota Press.

Newman, N., Fletcher, R., Kalogeropoulos, A., Levy, D. A. \& Nielsen, R. K. (2018). Reuters Institute Digital News Report 2018. Oxford: University of Oxford.

Nygaard, S. (2019). The Appearance of Objectivity: How Immigration-Critical Alternative Media Report the News, Journalism Practice, DOI: $10.1080 / 17512786.2019 .1577697$.

Marwick, A., \& Lewis, R. (2017). Media manipulation and disinformation online. Data \& Society Research Institute, retrieved from https://datasociety.net/research/mediamanipulation/.

Rauch, J. (2007). Activists as interpretive communities: Rituals of consumption and interaction in an alternative media audience. Media, Culture \& Society, 29(6), 994-1013.

Shoemaker, P. J., \& Reese, S. D. (2014). Mediating the message in the 21st century: A 
media sociology perspective. New York: Routledge.

Steindl, N., Lauerer, C., \& Hanitzsch, T. (2017). Journalismus in Deutschland. Aktuelle Befunde zu Kontinuität und Wandel im deutschen Journalismus [Journalism in Germany: Current findings on the continuity and change in German journalism]. Publizistik, 62(4), 401423. https://doi.org/10.1007/s11616-017-0378-9.

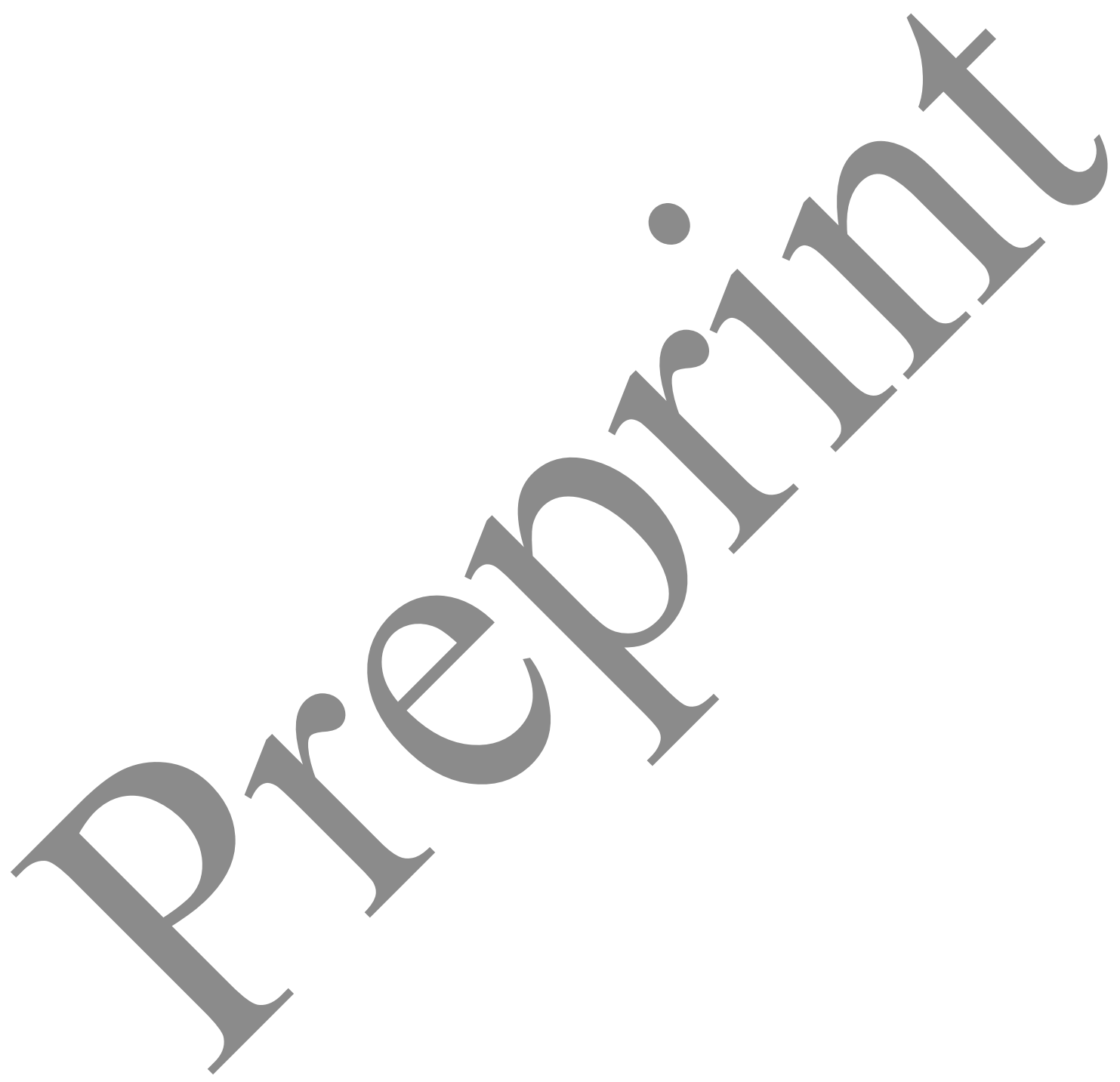

